\title{
Effects of canopy gaps on the genetic structure of Camellia japonica saplings in a Japanese old-growth evergreen forest
}

\author{
S Ueno ${ }^{1}, \mathrm{~N}$ Tomaru ${ }^{2}, \mathrm{H}$ Yoshimaru ${ }^{3}$, T Manabe ${ }^{4}$ and S Yamamoto ${ }^{2}$ \\ ${ }^{1}$ Genome Analysis Laboratory, Department of Forest Genetics, Forestry and Forest Products Research Institute, Tsukuba, Ibaraki 305- \\ 8687, Japan; '2aboratory of Forest Ecology and Physiology, Graduate School of Bioagricultural Sciences, Nagoya University, Nagoya \\ Aichi 464-8601, Japan; ${ }^{3}$ Ecological Genetics Laboratory, Department of Forest Genetics, Forestry and Forest Products Research Institute, \\ Tsukuba, Ibaraki 305-8687, Japan; 'Kitakyushu Museum of Natural History and Human History, 2-4-1 Higashida, Yahatahigashi-ku, \\ Kitakyushyu, Fukuoka 805-0071, Japan
}

The genetic structure of Camellia japonica saplings was investigated in relation to canopy conditions in an old-growth evergreen forest in Tsushima, Japan. To elucidate effects of canopy gaps on genetic structure, a 1 ha study site was divided into $20 \times 20 \mathrm{~m}$ quadrats, which were classified into a gap quadrats (GAP), closed canopy quadrats (CLS) and mixed quadrats. Five GAP quadrats and six CLS quadrats were analyzed separately. Isolation-by-distance was tested by examining the correlation between genetic distance and geographic distance. A significant positive correlation was detected for GAP quadrats, whilst that for CLS quadrats was significantly smaller and not significantly different from zero. On the other hand, an analysis using Moran's I spatial autocorrelation coefficients indicates that the genetic structure is weaker in GAP quadrats than in CLS quadrats in short distance classes. The values were significantly positive for both types of quadrat. These results, along with our field observations on flowering, suggest that canopy gaps affect the genetic structure of $C$. japonica saplings in two distinct ways. First, canopy gaps may promote flowering and mating in an isolation-by-distance manner within canopy gaps. Second, canopy gaps may promote seed production and resulting overlap in seed shadows may weaken fine-scale genetic structures.

Heredity (2006) 96, 304-310. doi:10.1038/sj.hdy.6800804; published online 1 March 2006

Keywords: Camellia japonica; microsatellites; canopy gaps; Moran's I; isolation-by-distance

\section{Introduction}

Genetic structure is a nonrandom association of genotypes or alleles resulting from the combined effects of ecological and genetic processes such as mutation, genetic drift, migration and selection. Colonization of new habitats is affected by many factors, including environmental conditions, interactions among organisms and the colonizing organism's dispersal mechanisms and capacity, which may have a genetic basis (Peroni, 1994; Trefilov et al, 2000). Subsequent establishment is affected by environmental heterogeneities that may favor different genotypes in different areas (Bradshaw, 1984). In plants, because of their sessile character, pollen- and seed-mediated gene flow is heavily responsible for plant population genetic structures (Epperson, 1989). Limited gene flow results in reproductive isolation and the accumulation of local genetic differences, first described by Wright (1943) as 'isolation by distance'. Since then, many studies have investigated isolation by distance, some of which have clearly demonstrated its occurrence in natural populations (Schaal, 1974; Slatkin, 1993; King

Correspondence: S Ueno, Genome Analysis Laboratory, Department of Forest Genetics, Forestry and Forest Products Research Institute, Tsukuba, Ibaraki 305-8687, Japan. E-mail: saueno@ffpri.affrc.go.jp

Received 1 October 2004; accepted 20 December 2005; published online 1 March 2006 et al, 2001). Wright further developed the shifting balance theory of evolution, and emphasized the importance of population subdivision in cases where gene flow is limited and genetic drift occurs (Wright, 1978). Analysis of genetic structure in natural populations may detect indicators of such evolutionary processes, and thus greatly help attempts to infer features of their evolutionary history that are both of intrinsic scientific interest and potentially useful for making decisions related to their conservation (Loveless and Hamrick, 1984; Linhart and Grant, 1996; Hogbin et al, 2000).

C. japonica L. is one of the most widely spread subcanopy tree species in evergreen forests, with a distribution ranging from the south and western coasts of the Korean Peninsula through Taiwan, Kyushu and Shikoku to Honshu of Japan (Kitamura and Murata, 1979). Allozyme studies have shown that high levels of genetic diversity are maintained in the species (Wendel and Parks, 1985; Chung and Kang, 1996). We have already studied the fine-scale genetic structure of $C$. japonica trees with a diameter at breast height (d.b.h.) $\geq 5 \mathrm{~cm}$ in an old-growth evergreen forest using microsatellite markers (Ueno et al, 2000). Spatial autocorrelation analysis revealed genetic structure within our 4 ha study plot, probably due to the limited, gravity-based seed dispersal of the species. Furthermore, we analyzed genetic structure for individuals with a d.b.h. $<5 \mathrm{~cm}$ and height between 30 and $32.5 \mathrm{~cm}$ (defined as JV1) and 
found strong genetic structure within this population. However, individuals with a d.b.h. $<5 \mathrm{~cm}$ and height between 103.8 and $200 \mathrm{~cm}$ (defined as JV2) did not show significant genetic structure. Individuals of JV2 seemed to cluster around canopy gaps, suggesting that canopy gaps may affect genetic structure to some extent (Ueno et al, 2002).

Canopy gaps, or simply 'gaps', are openings in the forest canopy that are created by natural disturbances, and represent one of the main elements of heterogeneity in forest ecosystems. Such heterogeneity generates various environmental conditions for seedling recruitment and establishment for many forest tree species (Yamamoto, 2000; Narukawa and Yamamoto, 2001; Hoshino et al, 2003). However, canopy gaps have been considered very rarely in population genetic studies. Although a few studies investigated genetic structures of the same species at different sites (Takahashi et al, 2000; Epperson and Chung, 2001), none of them have examined genetic structures of populations of the same species under different canopy conditions. This deficiency should be addressed, since there may be strong gradients of selective factors in and around canopy gaps, and thus strong microevolutionary forces. Therefore, studying the genetic structure of populations at such sites may provide interesting insights.

In this study, we investigated the genetic structure of $C$. japonica saplings in different canopy conditions in an old growth forest. The main objective was to clarify canopy gap effects on genetic structure. We hypothesized that preferential mating among individuals within gap areas may occur because the flowering activity of the adult individuals growing within them would tend to be higher than that of individuals growing under a closed canopy, and that fine-scale genetic structure would be weak in (and near) the forest gaps due to the overlapping of seed shadows. We defined gap quadrats and closed canopy quadrats in our 1 ha study site and based all analyses on data related to four highly polymorphic microsatellite loci. Isolation-by-distance was examined to test the first hypothesis and spatial autocorrelation to test the second hypothesis. The gap-related genetic results are discussed in relation to the flowering character of $C$. japonica.

\section{Materials and methods}

\section{Field methods and laboratory experiments}

The study site is in the Tatera Forest Reserve located on the South Island of Tsushima, between the Japanese Archipelago and the Korean Peninsula. A detailed description of the reserve can be found in a paper by Ito (1991). A 4-ha permanent plot $(200 \times 200 \mathrm{~m})$ was set up in 1990 in the reserve. Miura et al (2001) documented canopy openings by recording canopy gaps in squares in a $5 \times 5 \mathrm{~m}$ grid in the plot. They considered a grid-square with a canopy cover of $<30 \%$ as a gap square. In this study, a peripheral square was defined as one that had a border or a point touching a gap square. The gap and peripheral squares are considered gap areas (Figure 1). This definition of gap areas was adopted to allow both direct and indirect effects of canopy gaps to be included.

The flowering of all individual C. japonica trees with a diameter at d.b.h. $\geq 5 \mathrm{~cm}$ was recorded in February 1999 in a central 1 -ha core $(100 \times 100 \mathrm{~m})$ within the 4 ha plot.

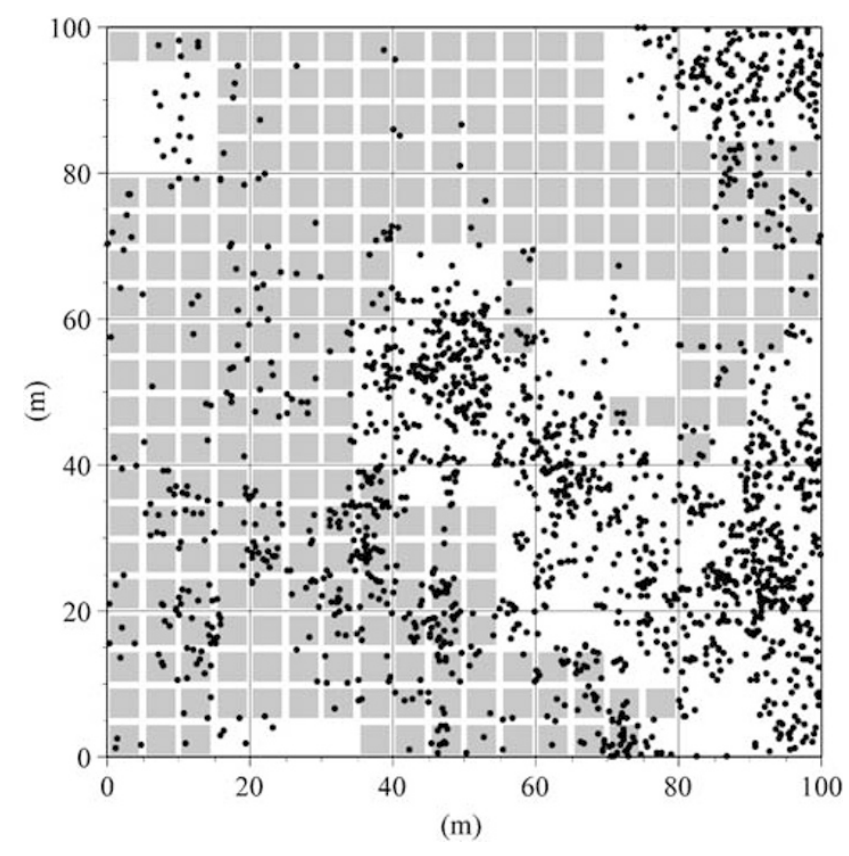

Figure 1 Locations of 1779 Camellia japonica saplings in the 1-ha core plot (marked with dots). The unshaded areas indicate gap areas, based on a census conducted in 1997.

This cutoff was applied because individuals with a d.b.h $<5 \mathrm{~cm}$ rarely flower at this study site. Indeed, at the census, none were observed to have flowered. The census had been performed to investigate canopy gap effects on flowering.

In 1999, all of the C. japonica individuals in the core plot with a d.b.h. $<5 \mathrm{~cm}$ in the height range from 30 to $200 \mathrm{~cm}$ were censused. The tree heights displayed an inverse J-shaped distribution, indicating demographic equilibrium (Ueno et al, 2002). In total, 2122 saplings were recorded in this area, and leaf samples for genetic analysis were collected. Genotypes at four microsatellite loci (Ueno et al, 1999) had already been determined for 348 individuals and published (Ueno et al, 2002). In this study, genotypes at these microsatellite loci were determined for a further 1431 saplings, and the data were pooled (Figure 1). The DNA extraction and genotyping procedures applied have been described in detail elsewhere (Ueno et al, 2000, 2002).

\section{Definition of quadrats}

The core plot was divided into 25 adjoining $20 \times 20 \mathrm{~m}$ quadrats and we treated all of the individuals within each quadrat as a single analysis unit. To characterize canopy gap effects on genetic structure, each quadrat was classified as a gap quadrat (GAP), a closed canopy quadrat (CLS), or a mixed quadrat (MIX). If more than $90 \%$ of individuals within a quadrat resided in a gap area, the quadrat was considered a GAP quadrat. If $<10 \%$ of individuals within a quadrat resided in a gap area, the quadrat was treated as a CLS quadrat. Other quadrats were treated as MIX quadrats. Furthermore, based on an analysis of aerial photographs of this study site (Fujita et al, 2003), we identified quadrats that may have experienced both gap and closed canopy conditions at various stages during the 32 years preceding the study. These quadrats were also regarded as MIX quadrats. The 
remaining GAP quadrats are likely to have been in gap conditions throughout the 32 years or to have experienced gap conditions at least twice during the period, while the remaining CLS quadrats are considered to have been under a closed canopy for this time. Moreover, we investigated the age of the trees by counting the annual rings of five trees grown under a closed canopy near the study plot. These individuals were arbitrary selected to represent the size range of seedlings in the present study. They were 30.6, 31.7, 112.7, 150.4, and $198.3 \mathrm{~cm}$ tall and their ages were 5, 5, 21, 17, and 28 years, respectively. Therefore, we considered that individuals in the GAP and CLS quadrats had grown under gap and closed canopy conditions, respectively, since their germination.

\section{Data analysis}

Only quadrats that contained more than 20 individuals were included in the analyses (Figure 2). Under this criterion, there were five GAP, six CLS and nine MIX quadrats. Separate analyses of genetic diversity and differentiation and spatial autocorrelation were only performed for GAP and CLS quadrats. MIX quadrats were excluded to avoid mixing the different canopy conditions. All calculations were carried out by computer programs written in-house in the $\mathrm{C}$ and $\mathrm{C}++$ programming languages (unpublished).

\section{Genetic diversity}

For each locus, the number of alleles detected $(A)$, observed heterozygosity $\left(H_{\mathrm{o}}\right)$ and expected heterozygosity $\left(H_{\mathrm{e}}\right)$ were calculated following Nei (1987). The FSTAT software package (Goudet, 1995) was used to calculate unbiased estimates for analogues of Wrights (1951) Fstatistics: $F_{\mathrm{IS}}, F_{\mathrm{IT}}$ and $F_{\mathrm{ST}}(f, F$ and $\theta)$ according to Weir and Cockerham (1984). To test $F_{\mathrm{IS}}$, alleles were randomized among individuals within quadrats, and to test $F_{\mathrm{IT}}$ alleles were permuted among quadrats. Differentiation among quadrats was tested with the log-likelihood statistic $G$ by randomizing genotypes among quadrats

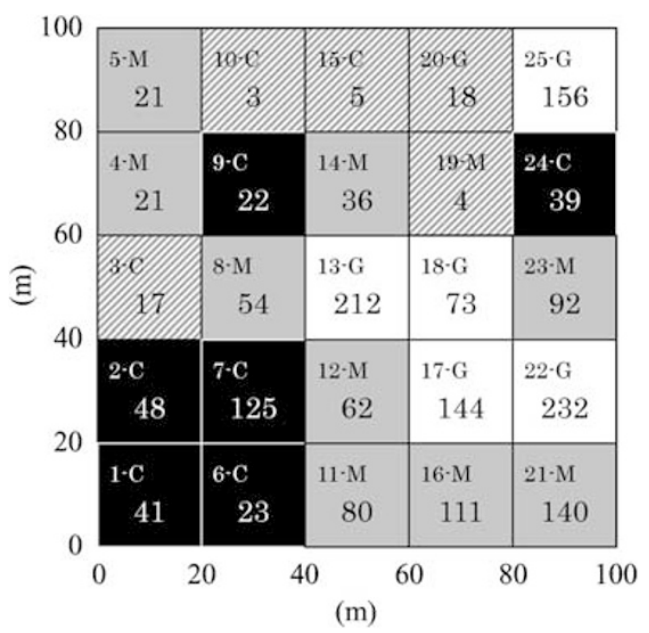

Figure 2 Locations of each quadrat and numbers of individuals within quadrats. Open, black, gray, and gray squares with oblique lines indicate GAP quadrats, CLS quadrats, MIX quadrats, and quadrats that were not analyzed, respectively. The designation of each quadrat is shown at the upper left corner of each quadrat. G, C, and $\mathrm{M}$ suffixes following the numbers, indicate GAP, CLS, and MIX, respectively.
(Goudet et al, 1996). Observed values were compared with those obtained from 1000 randomized data sets and $P$-values were determined. These tests were implemented by FSTAT (Goudet, 1995).

\section{Genetic distance and isolation by distance}

Nei's (1972) standard genetic distance $(D)$ for all four loci was calculated between pairs of quadrats, and the significance of the $D$ values was tested by randomization, with 1000 permutations of multilocus genotypes between pairs of quadrats. After each permutation, $D$ was recalculated and compared to the observed value. The relative frequency of cases leading to larger $D$ values than the observed values were taken as estimates of the probability of significant differentiation between the two quadrats. Levels of significance were adjusted for multiple simultaneous tests according to Rice (1989).

The extent of genetic differentiation and gene flow between quadrats was further examined in terms of isolation-by-distance. The location $(x, y)$ of each quadrat was defined as a gravity point of individuals within each quadrat and used for inter-quadrat distance calculations. To examine isolation-by-distance, the correlation of Nei's genetic distance and geographical distance between quadrats was investigated. Spearman's rank correlation coefficient $(r)$ was used as a test statistic. Three types of gene flow were considered and the correlation coefficient was calculated for each type. First, all quadrats (five GAPs, six CLSs and nine MIXs) were used in calculating the coefficient $\left(r_{\text {all }}\right)$. There were 190 quadrat pairs. This coefficient indicates stand-level isolation by distance. Second, a subset of the quadrat pairs was used to calculate $r$. Quadrat pairs that contained GAP (85 pairs) were used to calculate $r_{\mathrm{GAP}}$, which indicates the GAP component of isolation by distance. Third, in the same way, quadrat pairs that contained CLS (99 pairs) were used to calculate $r_{\mathrm{CLS}}$, which indicates the CLS component of isolation by distance. The difference $\left(d_{r}\right)$ in the correlation coefficient between $r_{\mathrm{GAP}}$ and $r_{\mathrm{GAP}}$ was used to indicate the degree of the discrepancy. To estimate the significance of the statistics, a Mantel (1967) test was conducted by 9999 randomizations. For each randomization, $r_{\text {all }}, r_{\mathrm{GAP}}, r_{\mathrm{CLS}}$ and $d_{r}$ were recalculated and compared to the observed values. The relative frequency of cases leading to less extreme coefficients than the respective observed values was used to assess the significance of the statistics.

\section{Spatial autocorrelation}

Fine scale genetic structure was analyzed, using Moran's I coefficients (Moran, 1950):

$$
I=\frac{n \sum_{i=1}^{n} \sum_{j \neq 1}^{n} w_{i j}\left(x_{i}-\bar{x}\right)\left(x_{j}-\bar{x}\right)}{W \sum_{i=1}^{n}\left(x_{i}-\bar{x}\right)^{2}},
$$

where $n$ is the number of individuals sampled, $x_{i}$ is the individual allele frequency of individual $i$ (1 if individual $i$ is homozygous for a given allele, 0.5 if the individual is heterozygous for the allele, and 0 if the individual has no copy of it), $\bar{x}$ is the mean value of $x_{i}$ for all individuals in the sample, $w_{i j}$ is 1 when the distance between individuals $i$ and $j$ is within the distance class under investigation, and zero otherwise. $W$ is the sum of all $w_{i j}$ values. In this study, 10 continuous distance classes, each of $2 \mathrm{~m}$, were considered, from 0-2 to $18-20 \mathrm{~m}$. Moran's I 
values were calculated only for alleles with a frequency $>5 \%$. An indication of the trends in spatial scale of genetic substructuring was obtained by creating plots (correlograms) of the change between distance classes (Sokal and Oden, 1978). The overall significance of the trend shown in the correlograms was tested according to Bonferroni criteria.

Average Moran's I coefficients were calculated for all alleles as a summary statistic. The average $I$ value was tested against the null hypothesis of no spatial autocorrelation by the method of randomization. The observed average $I$ was then compared to the randomized empirical distribution. The randomizations were conducted by randomly permuting multi-locus genotypes, while keeping their locations in the stand constant. These permutations were generated 1000 times and the average $I$ was calculated for each permutation. Furthermore, $95 \%$ confidence intervals for the average $I$ values were constructed by bootstrapping, as follows. Pairs of individuals in each distance class were resampled with replacement. The average $I$ values were then calculated for each of 1000 bootstraps, and the 25th and 975th largest bootstrap estimates were considered to define the 95\% confidence intervals.

\section{Results}

Flowering of individuals

The flowering of 183 individuals was recorded. In gap areas there were 80 individuals, 54 of which were flowering. In closed canopy areas, there were 103 individuals, 44 of which were flowering. There was no difference in averaged d.b.h between individuals of GAP and CLS (Welch two sample $t$-test, $P=0.083$ ). Logistic regression model, in which flowering was described by site condition (GAP or CLS) and d.b.h., explained that both factors affected significantly. Odds of flowering for GAP individuals were 4.69 times higher than that for CLS individuals.

\section{Genetic diversity}

Similar levels of genetic diversity were observed among GAP and CLS quadrats (Table 1). More alleles were

Table 1 Genetic diversity and differentiation measures for (a) GAP and (b) CLS quadrats

\begin{tabular}{lcccccc}
\hline Locus & $\mathrm{A}$ & $\mathrm{H}_{o}$ & $\mathrm{H}_{e}$ & $\mathrm{~F}_{I T}$ & $\mathrm{~F}_{S T}$ & $\mathrm{~F}_{I S}$ \\
\hline (a) GAP & & & & & & \\
MSCjaF25 & 15 & 0.863 & 0.843 & -0.021 & 0.011 & -0.032 \\
MSCjaF37 & 18 & 0.723 & 0.794 & $0.091^{* * *}$ & 0.011 & $0.081^{* * *}$ \\
MSCjaH38 & 14 & 0.812 & 0.819 & 0.013 & 0.019 & -0.006 \\
MSCjaH46 & 16 & 0.628 & 0.679 & $0.083^{* * *}$ & 0.040 & $0.045^{* *}$ \\
All loci & 15.75 & 0.756 & 0.784 & $0.039^{* * *}$ & 0.019 & $0.020^{* *}$ \\
& & & & & & \\
(b) CLS & & & & & & \\
MSCjaF25 & 14 & 0.859 & 0.836 & -0.022 & 0.024 & -0.047 \\
MSCjaF37 & 14 & 0.799 & 0.833 & $0.047^{*}$ & 0.024 & 0.023 \\
MSCjaH38 & 14 & 0.879 & 0.868 & -0.004 & 0.034 & -0.039 \\
MSCjaH46 & 13 & 0.732 & 0.712 & -0.022 & 0.022 & -0.044 \\
All loci & 13.75 & 0.817 & 0.812 & 0.001 & 0.026 & -0.026
\end{tabular}

The number of individuals analyzed was 817 and 298 for GAP and CLS, respectively. The significance of $F_{\mathrm{IT}}$ and $F_{\mathrm{IS}}$ values is indicated by asterisks $\left({ }^{*} P<0.05 ;{ }^{* *} P<0.01 ;{ }^{* * *} P<0.001\right)$. detected in GAP, probably due to the larger number of individuals contained in the GAP than in the CLS quadrats (817 and 298, respectively). Observed and expected heterozygosities may be higher in CLS than in GAP. However, since only four loci were examined the statistical significance of the differences was not determined. There were significant departures of $F_{\text {IT }}$ and $F_{\text {IS }}$ from Hardy-Weinberg expectations for the loci MSCjaF37, MSCjaH46 and over all loci in GAP and for the locus MSCjaF37 in CLS quadrats. Differentiation tests with $G$ statistics indicated significant differentiation among quadrats in both GAP and CLS for all loci $(P<0.001)$.

\section{Genetic distance and isolation by distance}

Nei's genetic distance was calculated for 10 and 15 GAP and CLS pairs of quadrats, respectively. Significant differentiation between quadrats was found for 90 and $53 \%$ of the GAP and CLS pairs, respectively (Table 2).

A Mantel test revealed a significant correlation between the pair-wise genetic distance $(D)$ and geographical distance for stand-level and the GAP component $\left(r_{\mathrm{all}}=0.355, \quad P=0.0030\right.$ and $r_{\mathrm{GAP}}=0.519, \quad P=0.0003$; Figure $3 a$ and $b$, respectively), while the correlation coefficient for the CLS component proved to be nonsignificant $\left(r_{\mathrm{CLS}}=0.195, P=0.1177 ;\right.$ Figure $\left.3 \mathrm{c}\right)$. The difference of the correlation coefficient between GAP and CLS was also significant $\left(d_{r}=0.324, P=0.0148\right)$.

\section{Spatial autocorrelation}

Spatial autocorrelation analysis was carried out for 20 and 25 alleles in GAP and CLS quadrats, respectively, yielding 450 separate $I$ values (45 alleles in total $\times 10$ distance classes). Average $I$ correlograms are shown in Figure 4 along with $95 \%$ confidence envelopes calculated on the basis of the randomized distribution of the statistics. The $95 \%$ confidence interval about the average $I$ for each distance class was overlaid in the same figure. For GAP quadrats, the average Moran's I value in all distance classes showed a significant positive trend. For CLS quadrats, the average Moran's $I$ value in the first to seventh distance classes $(0-2 \mathrm{~m}$ to $12-14 \mathrm{~m})$ showed a

Table 2 Nei's (1972) genetic distance (below diagonal) and its significance (above diagonal) for (a) GAP and (b) CLS quadrats

\begin{tabular}{lcccccc}
\hline Designation & $13-G$ & $17-G$ & $18-G$ & $22-G$ & $25-G$ & \\
\hline $\begin{array}{l}\text { (a) GAP } \\
\text { 13-G }\end{array}$ & & & & & & \\
17-G & 0.037 & & NS & $* *$ & $* *$ & \\
18-G & 0.059 & 0.023 & & $* *$ & $* *$ & \\
22-G & 0.111 & 0.059 & 0.071 & & $* *$ & \\
25-G & 0.090 & 0.069 & 0.085 & 0.101 & & \\
& & & & & & \\
Designation & $1-C$ & $2-C$ & $6-C$ & $7-C$ & $9-C$ & $24-C$ \\
\hline (b) CLS & & & & & & \\
1-C & & NS & NS & $* *$ & $*$ & NS \\
2-C & 0.101 & & $* *$ & $* *$ & $* *$ & NS \\
6-C & 0.125 & 0.252 & & NS & $*$ & NS \\
7-C & 0.152 & 0.216 & 0.103 & & $* *$ & $*$ \\
9-C & 0.202 & 0.294 & 0.188 & 0.163 & & NS \\
24-C & 0.101 & 0.137 & 0.097 & 0.083 & 0.126 & \\
\hline
\end{tabular}

The designation for each quadrat follows Figure 2. NS, nonsignificant; ${ }^{*} P<0.05 ;{ }^{* *} P<0.01$. 

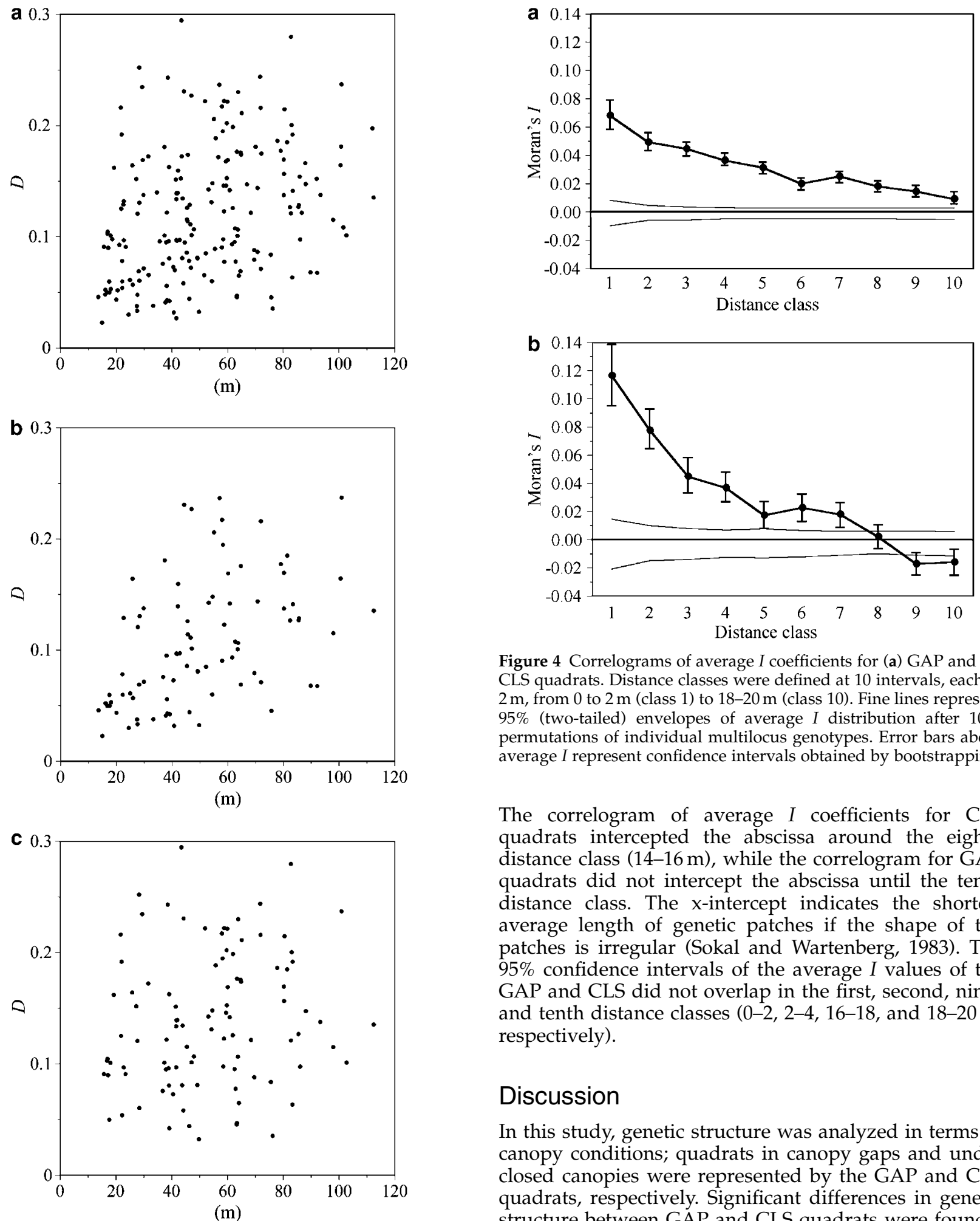

Figure 3 Isolation by distance. Nei's genetic distance $(D)$ is plotted against the geographical distance. (a) Stand level, (b) the GAP component, (c) the CLS component.

significant positive trend, while that in the 10th distance classes showed a significant negative trend. The correlograms for GAP and CLS quadrats were both significant at the 5\% probability level after Bonferroni correction.

Figure 4 Correlograms of average $I$ coefficients for (a) GAP and (b) CLS quadrats. Distance classes were defined at 10 intervals, each of $2 \mathrm{~m}$, from 0 to $2 \mathrm{~m}$ (class 1 ) to $18-20 \mathrm{~m}$ (class 10). Fine lines represent 95\% (two-tailed) envelopes of average $I$ distribution after 1000 permutations of individual multilocus genotypes. Error bars about average $I$ represent confidence intervals obtained by bootstrapping.

The correlogram of average $I$ coefficients for CLS quadrats intercepted the abscissa around the eighth distance class (14-16 m), while the correlogram for GAP quadrats did not intercept the abscissa until the tenth distance class. The $x$-intercept indicates the shortest average length of genetic patches if the shape of the patches is irregular (Sokal and Wartenberg, 1983). The 95\% confidence intervals of the average $I$ values of the GAP and CLS did not overlap in the first, second, ninth and tenth distance classes $(0-2,2-4,16-18$, and $18-20 \mathrm{~m}$, respectively).

\section{Discussion}

In this study, genetic structure was analyzed in terms of canopy conditions; quadrats in canopy gaps and under closed canopies were represented by the GAP and CLS quadrats, respectively. Significant differences in genetic structure between GAP and CLS quadrats were found.

\section{Genetic diversity}

The $F_{\text {IT }}$ values for GAP were significantly positive for MSCjaF37, MSCjaH46 and over all loci, while for CLS, only the $F_{\mathrm{IT}}$ for locus MSCjaF37 was significantly positive and the other $F_{\mathrm{IT}}$ and $F_{\mathrm{IS}}$ values were negative. GAP conditions promoted flowering of $C$. japonica and the proportion of flowering individuals in GAP quadrats was significantly higher than the corresponding figure in 
CLS quadrats. In GAP quadrats, mating between near parents may preferentially occur, forming local breeding units, and may result in departures from HardyWeinberg equilibrium. However, the negative $F_{\text {IS }}$ value for the MSCjaF25 locus in the GAP quadrats was difficult to explain, because the Wahlund effect due to population substructure should theoretically affect all loci. Increasing the number of loci may help elucidate this situation. There was significant differentiation in both GAP and CLS quadrats for all loci, according to the $G$ statistics. However, this test was not informative for characterizing gap effects.

\section{Genetic distance and isolation-by-distance}

The analysis of Nei's genetic distance between quadrats detected more significant genetic distances in GAP than in CLS quadrats (Table 2). Furthermore, the correlations of genetic distance and geographical distance clearly showed isolation-by-distance in GAP quadrats (Figure $3 b$ ), indicating that gene flow between neighboring quadrats is extensive and that the levels of gene flow decreases as geographic distance increases. For CLS quadrats there was no significant relationship between genetic distance and geographical distance (Figure 3c). Moreover, significant difference in the correlation coefficient between GAP and CLS was detected. This discrepancy in isolation-by-distance between GAP and CLS quadrats may indicate differences in their levels of pollen dispersal, because seeds of $C$. japonica are primarily dispersed by gravity, so seed dispersal parameters are expected to be similar in GAP and CLS quadrats. Canopy gaps are likely to create favorable environmental conditions for flowering and thus raise the proportion of flowering individuals. Our field observations indicated that birds visited flowers of $C$. japonica and that they are possible pollinators of $C$. japonica. Kunitake et al (2004) suggest that the main pollinator of $C$. japonica is a bird species (Zosterops japonica). Blooming of C. japonica around canopy gaps is likely to attract pollinators. Consequently, mating between neighboring adults may be promoted in GAP conditions. On the other hand, mating in CLS conditions may be more haphazard and flowers in CLS quadrats may receive pollen from distant individuals.

\section{Spatial autocorrelation}

Individuals in GAP quadrats probably produced many offspring because flowering was promoted in GAP conditions. The density of saplings in GAP quadrats was higher than that in CLS quadrats (Mann-Whitney $U$ test, $P=0.003$ ). Consequently, seed shadows may overlap more extensively in GAP than in CLS quadrats. Overlapping seed shadows generally blur genetic structure (Hamrick et al, 1993). The smaller spatial autocorrelation coefficients in GAP quadrats in the first distance class $(0-2 \mathrm{~m})$ may reflect the extensive overlapping of their seed shadows, although high levels of dispersal may also lower the autocorrelation in smaller distance classes. The $\mathrm{x}$-interception of the correlograms (Figure 4) suggested that GAP quadrats had larger genetic patches than CLS quadrats. The average Moran's I for each locus also showed similar trend (data not shown). The larger genetic patch in GAP quadrats is likely to be the high levels of pollen flow among neighboring quadrats.
Finally, we summarize the effects of canopy gaps on the genetic structure of $C$. japonica saplings in two main points. First, canopy gaps are likely to promote flowering and mating in an isolation-by-distance manner within canopy gaps. Second canopy gaps are likely to promote seed production and the resulting overlapping seed shadows, thereby weakening fine-scale genetic structure.

The evolutionary consequences of these gap effects are unclear. Canopy gaps may create local breeding units. Investigations of adaptive traits such as the germination rate in relation to gap dynamics may be needed to clarify whether (and if so how) canopy gaps affect the evolution of C. japonica.

\section{Acknowledgements}

Financial support was provided by a Grant-in-Aid for Scientific Research $(10354013,11460069)$ from the Ministry of Education, Science, Sports and Culture of Japan. $S$ Kanetani, D Hoshino, $M$ Miura, $T$ Fujita and $\mathrm{N}$ Nishimura, whose help is gratefully acknowledged, provided assistance in the field. We thank the Tsushima District Forest Office for allowing us to conduct this survey and K Shimatani for valuable discussions.

\section{References}

Bradshaw AD (1984). Ecological significance of genetic variation between populations. In: Dirzo R, Sarukhan J (eds) Perspectives on Plant Population Ecology. Sinauer Assorciates: Sunderland, Mass. pp 213-228.

Chung MG, Kang SS (1996). Genetic variation within and among populations of Camellia japonica (Theaceae) in Korea. Can I For Res 26: 537-542.

Epperson BK (1989). Spatial patterns of genetic variation within plant populations. In: Brown AHD, Clegg MT, Kahler AL, Weir BS (eds) Plant Population Genetics, Breeding and Genetic Resources. Sinauer Associates: MA. pp 229-253.

Epperson BK, Chung MG (2001). Spatial genetic structure of allozyme polymorphisms within populations of Pinus strobus (Pinaceae). Am J Bot 88: 1006-1010.

Fujita T, Itaya A, Miura M, Manabe T, Yamamoto S (2003). Longterm canopy dynamics analysed by aerial photographs in a temperate old-growth evergreen broad-leaved forest. J Ecol 91: 686-693.

Goudet J (1995). FSTAT (Version 1.2): a computer program to calculate F-statistics. J Hered 86: 485-486.

Goudet J, Raymond M, de Meeus T, Rousset F (1996). Testing differentiation in diploid populations. Genetics 144 1933-1940.

Hamrick JL, Murawski DA, Nason JD (1993). The influence of seed dispersal mechanisms on the genetic structure of tropical tree populations. Vegetatio 107/108: 281-297.

Hogbin PM, Peakall R, Sydes MA (2000). Achieving practical outcomes from genetic studies of rare Australian plants. Aust $J$ Bot 48: 375-382.

Hoshino D, Nishimura N, Yamamoto S (2003). Effects of canopy conditions on the regeneration of major tree species in an old-growth Chamaecyparis obtusa forest in central Japan. For Ecol Manag 175: 141-152.

Ito $S$ (1991). Species turnover and diversity patterns along an evergreen broad-leaved forest coenocline. J Vegetation Sci $\mathbf{2}$ 477-484.

King TL, Kalinowski ST, Schill WB, Spidle AP, Lubinski BA (2001). Population structure of Atlantic salmon (Salmo salar L.): a range-wide perspective from microsatellite DNA variation. Mol Ecol 10: 807-821.

Kitamura S, Murata G (1979). Coloured Illustrations of Woody Plants of Japan. Hoikusha Publishing Co., LTD.: Osaka. 
Kunitake YK, Hasagawa M, Miyashita T, Higuchi H (2004). Role of seasonally specialist bird Zosterops japonica on pollen transfer and reproductive success of Camellia japonica in a temperate area. Plant Species Biol 19: 197-201.

Linhart YB, Grant MC (1996). Evolutionary significance of local genetic differentiation in plants. Annu Rev Ecol Syst 27: 237-277.

Loveless MD, Hamrick JL (1984). Ecological determinants of genetic structure in plant populations. Annu Rev Ecol Syst $\mathbf{1 5}$ 65-95.

Mantel N (1967). The detection of disease clustering and a generalized regression approach. Cancer Res 27: 209-220.

Miura M, Manabe T, Nishimura N, Yamamoto S (2001). Forest canopy and community dynamics in a temperate old-growth evergreen broad-leaved forest, South-Western Japan: a 7-year study of a 4-ha plot. J Ecol 89: 841-849.

Moran PAP (1950). Notes on continuous stochastic phenomena. Biometrika 37: 17-23.

Narukawa Y, Yamamoto S (2001). Gap formation, microsite variation and the conifer seedling occurrence in a subalpine old-growth forest, central Japan. Ecol Res 16: 617-625.

Nei M (1972). Genetic distance between populations. Am Nat 106: $283-292$

Nei M (1987). Molecular Evolutionary Genetics. Columbia University Press: New York.

Peroni PA (1994). Seed size and dispersal potential of Acer rubrum (Aceraceae) samaras produced by populations in early and late successional environments. Am J Bot $\mathbf{8 1}$ $1428-1434$.

Rice WR (1989). Analyzing tables of statistical tests. Evolution 43: 223-225.

Schaal BA (1974). Isolation by distance in Liatris cylindracea. Nature 252: 703.

Slatkin M (1993). Isolation by distance in equilibrium and nonequilibrium populations. Evolution 47: 264-279.
Sokal RR, Oden NL (1978). Spatial autocorrelation in biology 1. Methodology. Biol J Linn Soc Lond 10: 199-228.

Sokal RR, Wartenberg DE (1983). A test of spatial autocorrelation analysis using an isolation-by-distance model. Genetics 105: 219-237.

Takahashi M, Mukouda M, Koono K (2000). Differences in genetic structure between two Japanese beech (Fagus crenata Blume) stands. Heredity 84: 103-115.

Trefilov A, Berard J, Krawczak M, Schmidtke J (2000). Natal dispersal in rhesus macaques is related to serotonin transporter gene promoter variation. Behav Genet 30: 295-301.

Ueno S, Tomaru N, Yoshimaru $\mathrm{H}$, Manabe T, Yamamoto S (2000). Genetic structure of Camellia japonica L. in an old-growth evergreen forest, Tsushima, Japan. Mol Ecol 9: 647-656.

Ueno S, Tomaru N, Yoshimaru $\mathrm{H}$, Manabe $\mathrm{T}$, Yamamoto $\mathrm{S}$ (2002). Size-class differences in genetic structure and individual distribution of Camellia japonica L. in a Japanese oldgrowth evergreen forest. Heredity 89: 120-126.

Ueno S, Yoshimaru H, Tomaru N, Yamamoto S (1999). Development and characterization of microsatellite markers in Camellia japonica L. Mol Ecol 8: 335-336.

Weir BS, Cockerham CC (1984). Estimating F-statictcs for the analysis of population structure. Evolution 38: 1138-1370.

Wendel JF, Parks CR (1985). Genetic diversity and population structure in Camellia japonica L. (Theaceae). Am J Bot 72: 52-65.

Wright S (1943). Isolation by distance. Genetics 28: 114-138.

Wright S (1951). The genetical structure of populations. Eugenics 15: 323-354.

Wright S (1978). Evolution and the Genetics of Populations, Vol. 4 Variability within and among natural populations, University of Chicago Press: Chicago.

Yamamoto S (2000). Forest gap dynamics and tree regeneration. J For Res 5: 223-229. 